\title{
Flexural Behavior of Casing Joint of Square Steel Tube
}

\author{
Jinsan Ju ${ }^{1}$, Zhenhua Hou ${ }^{1}$, Xiugen Jiang ${ }^{1}$, Yuzhi $\mathrm{He}^{1}$, Guangkui Zhang ${ }^{1}$, Zichen Lin $^{2}$ and \\ Min Ding ${ }^{1, *}$
}

${ }^{1}$ Department of Civil Engineering, China Agricultural University, Beijing 100083, China
${ }^{2}$ School of Soil and Water Conservation, Beijing Forestry University, Beijing 100083, China

\begin{abstract}
The tests on thirteen specimens of casing joints of square steel tube were conducted to investigate the flexural behavior of the joints. At the same time, the numerical simulation studies on that of the joints were carried out by using finite element analysis software ANSYS/LS-DYNA with consideration of geometric nonlinearity, material nonlinearity and contact nonlinearity. On this basis, the effects of tube wall thickness, tube edge length, and inserting depth on failure mode, ultimate flexural capacity and deformation of casing joint of square steel tube was discussed. The results show that there are two types of failure modes, i.e., inside tube yield failure and outside tube shear failure, when the joints are subjected to lateral load. Ultimate flexural capacity and rigidity of casing joint of square steel tube increased with the inserting depth increasing. The ultimate flexural capacity of the joint is proportional to tube shear strength, tube wall thickness, inserting depth, and tube edge length. The fruits are useful to the design and application of casing joints of square steel tube.
\end{abstract}

Keywords: Casing joint, flexural behavior, experiment, numerical simulation.

\section{INTRODUCTION}

With the development of light steel structure study, steel tube structure gets more attention in the modern engineering structure, in which the square tube structure is very popular. The casing joint studied in this paper is different with the traditional joints of steel structure. It fixes or connects structures by inserting depth without welding and bolts. This type of joint has been widely used in agricultural building such as green-house etc. due to its easy fabrication and installation. Furthermore, it has better prospective in other types of structures (for instance, the flag pole).

Currently there are many achievements of study on the properties of tubular joint, especially for steel tubular intersecting joint. In 1974 some studies on multi-planar joints have already been carried out. M. Yajima et al. [1] measured the bearing capacity of $4 \mathrm{KK}$ circular tube joints subject to axial loads. Japanese professor J. C. Paul [2] carried out axial load test on 12 TT space tube joints. K. J. R. Rasmussen [3] summarized the testing results of $K$ and $X$ joints which are made of stainless steel in 1990 in Sydney. On this basis, some advises were put forward on stainless steel design which provided reference to the new steel structure engineering codes in Australia. R. J. Qian [4] developed the research on cracking direction on the surface of $T$ tube joint with the theory of density factor theory of strain energy. M. R.

\footnotetext{
*Address correspondence to this author at the Department of Civil Engineering, China Agricultural University, Beijing 100083, China; Tel: +86-010-62737130 (Office), +86-15901504286 (Mobile); Fax: +86-010-62736526;

E-mails: dingmin@cau.edu.cn,dingmin2008@gmail.com
}

Morgan, et al. [5] analyzed the stress concentration of $\mathrm{K}$ tube joint simulated by thin shell element subject to axial load. C. K. Lee et al. [6] concluded a precise and effective finite element model to solve the problems of T, Y, K tubular joints destruction. Y. S. Choo et al. [7] studied the static responses of $\mathrm{K}$ joints of thick wall tube with different boundary conditions and different axial load in truss chord.

But only a little study on casing and dowel joint of square steel tube were carried out. B. Shen [8] studied on casing members of which the inside main tube bear with the axial compressive force and outside tube constrains the yield deformation of inside main tube to raise the axial bearing capacity and improve the post-buckling behavior. L. L. Zhang [9] used the software ANSYS with consideration of material nonlinearity and geometric nonlinearity to study the capacity and rigidity of casing joint of circular steel tube. Y. H. Wu [10] used the software ANSYS to develop the behavior of casing joint of square steel tube with the model of cantilever structure.

When the casing joints of steel tube is subject to bending moment, the flexural rigidity, loads, and vertical displacement of joints have some relationship which is directly related with mechanical properties of steel tubular joints. In this paper, Experimental studies on flexural behavior of casing joint of square steel tube will be conducted and the finite element analysis software ANSYS/LS-DYNA will be used to do the numerical simulation. On this basis, the flexural failure mode, ultimate load, flexural rigidity and its effecting factors will be discussed and the achievement will benefit the design and implementation of casing and dowel joint of square steel tube. 


\section{EXPERIMENTAL STUDY}

\subsection{Specimens}

The cold-formed thin-walled steel usually used in greenhouses was chosen as the specimen material and there are two types of casing joints according to the different edge length of square tube, one is 20-25 and another is 25-30. Depending on tube wall thickness and inserting depth, 13 specimens were designed of which the parameters are presented in Table 1. The specimens of casing joints of square steel tube are shown as Fig. (1).

\subsection{Material Properties}

Due to the small size of tube cross-section, stretching single square steel tube was used to measure its mechanical performance according to the code GB-T2282002. And the details of the specimens are shown in Fig. (2). The material performance test has three specimens. The mechanical properties of the tube are listed in Table $\mathbf{2}$.

\subsection{Loading Mode}

The RAT-50 hydraulic universal testing machine was used to loading. To simulate the actual conditions of casing joint of square steel tube, two end of the specimen was simply supported and subjected to lateral concentrated load at the mid-span as shown in Fig. (3).

\subsection{Measurements}

The following two types of data were measured:

(1) Ultimate concentrated load: Read from the meter of WE-100 testing machine.

Table 1. Specimens

\begin{tabular}{|c|c|c|c|c|c|}
\hline $\begin{array}{l}\text { Specimen } \\
\text { Number }\end{array}$ & $\begin{array}{c}\text { Edge Length of } \\
\text { inside Tube (mm) }\end{array}$ & $\begin{array}{l}\text { Wall Thickness of } \\
\text { inside Tube }(\mathrm{mm})\end{array}$ & $\begin{array}{c}\text { Edge Length of } \\
\text { outside Tube (mm) }\end{array}$ & $\begin{array}{l}\text { Wall Thickness of } \\
\text { outside Tube (mm) }\end{array}$ & $\begin{array}{c}\text { Inserting } \\
\text { Depth }(\mathbf{m m})\end{array}$ \\
\hline $25-20-1-1$ & 20 & 1 & 25 & 1 & 20 \\
\hline $25-20-2-1$ & 20 & 1 & 25 & 1 & 40 \\
\hline $25-20-3-1$ & 20 & 1 & 25 & 1 & 60 \\
\hline $25-20-2-2$ & 20 & 2 & 25 & 2 & 40 \\
\hline $25-20-3-2$ & 20 & 2 & 25 & 2 & 60 \\
\hline $25-20-4-2$ & 20 & 2 & 25 & 2 & 80 \\
\hline $30-25-1-2$ & 25 & 2 & 30 & 2 & 25 \\
\hline $30-25-4-2$ & 25 & 2 & 30 & 2 & 100 \\
\hline $30-25-5-2$ & 25 & 2 & 30 & 2 & 125 \\
\hline $30-25-6-2$ & 25 & 2 & 30 & 2 & 150 \\
\hline
\end{tabular}

Fig. (1). Specimens of casing joints of square steel tube.

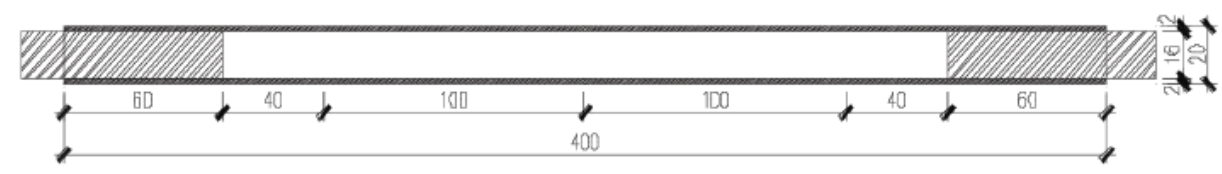

(a) Working drawing

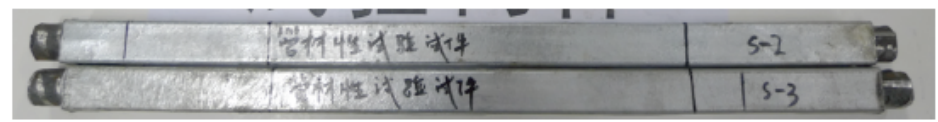

(b) The specimen

Fig. (2). Details of specimens for square steel tube material performance test. 
Table 2. Mechanical Properties of Material

\begin{tabular}{|c|c|c|c|}
\hline & Ultimate Stress (MPa) & Yielding Stress $(\mathbf{M P a})$ & Ultimate Strain $(\mu \varepsilon)$ \\
\hline \hline Tube tensile behavior & 327.52 & 291.19 & 0.16 \\
\hline
\end{tabular}

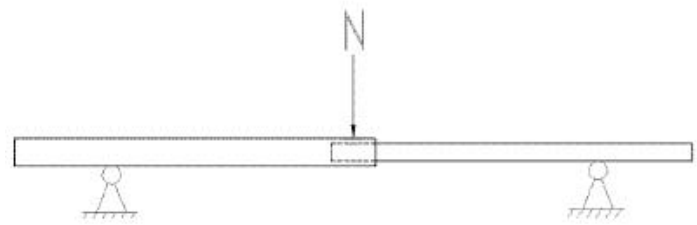

(a) Schematic diagram of loading

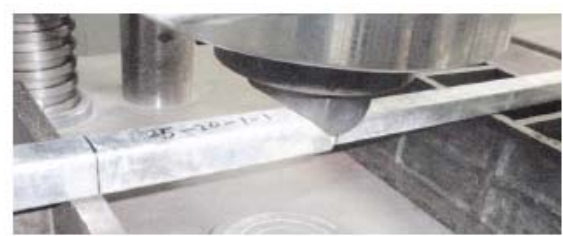

(b) View of test loading

Fig. (3). Test loading.

(2) Ultimate vertical displacement of the specimen: Read from the rising or falling height of the hydrocylinder of the testing machine.

\subsection{Results}

The testing results of casing joint of square steel tube are shown in Table 3. The error $=$ (theoretical value of single tube-measured value)/measured value $\times 100 \%$. The theoretical value of single tube was calculated by using single tube simply supported beam with the same span, according to the tube ultimate strength.

Table 3 shows that the ultimate load and displacement of casing joint of square steel tube is higher than that of single tube. The failure modes of 25-20-2-2, 25-20-3-2, 25-20-4-2, $30-25-1-2,30-25-2-2$ are outside tube shear failure. This type of failure mode had no any sign before it occurred, belong to brittle failure. But failure modes of the other ten specimens are all inside tube yield failure which had significant yield deformation before it occurred, belonging to ductile failure.

\section{NUMERICAL SIMULATION}

\subsection{Model}

The finite element analysis software ANSYS/LS-DYNA was used to do the 1:1 numerical simulation of casing joint of square steel tube. In this model, a rigid body was used to imposing the concentrated load at mid-span of the joints with two end simply supported. The model is shown as Fig. (4).

\subsection{Principle of the Model \\ (1) Constitutive Equation}

In this paper, the segmental linear plastic model of LSDYNA suitable to steel is used in which the stress-strain

Table 3. Results of the Experiment

\begin{tabular}{|c|c|c|c|c|c|c|c|}
\hline \multirow{2}{*}{$\begin{array}{l}\text { Specimen } \\
\text { Number }\end{array}$} & \multicolumn{3}{|c|}{ Ultimate Load (kN) } & \multicolumn{3}{|c|}{ Ultimate Displacement (mm) } & \multirow[b]{2}{*}{ Failure Mode } \\
\hline & Measured Value & $\begin{array}{c}\text { Theoretical Value of } \\
\text { Single Tube }\end{array}$ & Errors & Measured Value & $\begin{array}{c}\text { Theoretical Value of } \\
\text { Single Tube }\end{array}$ & Errors & \\
\hline $25-20-1-1$ & 2.25 & 2 & $-11.11 \%$ & 21 & 23.7 & $12.86 \%$ & Inside tube yield failure \\
\hline $25-20-2-1$ & 2.25 & 2 & $-11.11 \%$ & 36 & 23.7 & $-34.17 \%$ & Inside tube yield failure \\
\hline $25-20-3-1$ & 2.5 & 2 & $-20.00 \%$ & 21 & 23.7 & $12.86 \%$ & Inside tube yield failure \\
\hline $25-20-4-1$ & 2.5 & 2 & $-20.00 \%$ & 12 & 23.7 & $97.50 \%$ & Inside tube yield failure \\
\hline $25-20-2-2$ & 4.5 & 3.44 & $-23.56 \%$ & 40 & 23.8 & $-40.50 \%$ & Outside tube shear failure \\
\hline $25-20-3-2$ & 5.25 & 3.44 & $-34.48 \%$ & 31 & 23.8 & $-23.23 \%$ & Outside tube shear failure \\
\hline $25-20-4-2$ & 4.15 & 3.44 & $-27.58 \%$ & 13 & 23.8 & $83.08 \%$ & Outside tube shear failure \\
\hline $30-25-1-2$ & 1.725 & 5.71 & $231.01 \%$ & 33.5 & 19 & $-43.28 \%$ & Outside tube shear failure \\
\hline $30-25-2-2$ & 6.5 & 5.71 & $-12.15 \%$ & 17 & 19 & $11.76 \%$ & Outside tube shear failure \\
\hline $30-25-3-2$ & 7.45 & 5.71 & $-23.36 \%$ & 15.5 & 19 & $22.58 \%$ & Inside tube yield failure \\
\hline $30-25-4-2$ & 7.025 & 5.71 & $-17.55 \%$ & 18.25 & 19 & $4.11 \%$ & Inside tube yield failure \\
\hline $30-25-5-2$ & 8.6 & 5.71 & $-33.60 \%$ & 24.25 & 19 & $-21.65 \%$ & Inside tube yield failure \\
\hline $30-25-6-2$ & 7.075 & 5.71 & $-19.29 \%$ & 29.5 & 19 & -35.59 & Inside tube yield failure \\
\hline
\end{tabular}




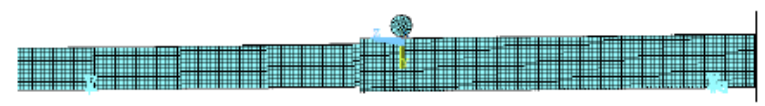

Fig. (4). Numerical simulation model.

curve related with strain rate can be input. Failure can be defined by plastic strain.

\section{(2) Element Type}

Both to the inside tube and outside tube of casing joint of square steel tube, shell element is suitable to be used for the simulation. Therefore, the shell element SHELL163 in ANSYS/LS-DYNA is chosen.

\section{(3) Contact Type}

Surface-surface contact type was used with the consideration of tube local yield failure and outside tube shear failure.

\section{RESULT COMPARISON}

\subsection{Failure Mode}

The test results show that there are two failure modes when casing joints of square steel tube are subjected to lateral load. The first failure mode is outside tube shear failure as shown in Fig. $(\mathbf{5}(\mathbf{a}))$, and the second is inside tube yield failure as shown in Fig. (5(b)). Fig. (5) also presents the failure mode comparison of simulation results and test results. It can be seen that the simulation results can well fit the test results.

\subsection{Ultimate Load and Displacement}

The simulation results showed that the vertical displacement increased quickly and unstably after the first element failure occurred. Then the simulated ultimate load and displacement in the following parts is defined when the

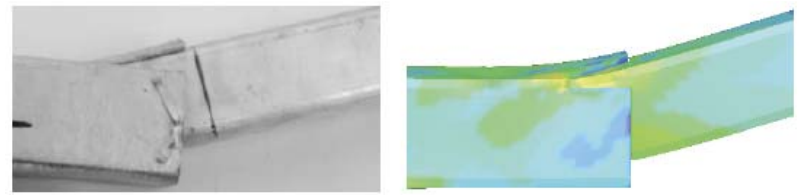

(a) Outside tube shear failure

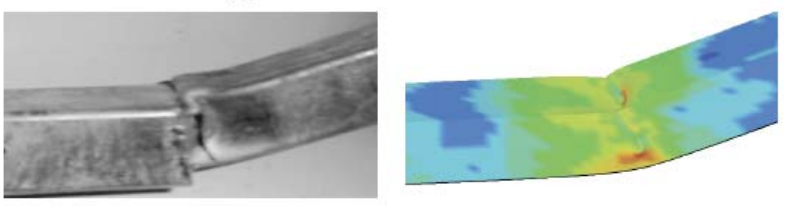

(b) Inside tube yield failure

Fig. (5). Failure modes of the joints.

first element failure occurs. The comparisons of test results and simulation results of ultimate load and displacement are shown in Table 4. The error $=$ (measured value-simulated value)/measured value $\times 100 \%$. From Table $\mathbf{4}$, it can be seen the test results and simulation results fit well.

\subsection{Analysis of Ultimate Load}

\section{(1) Effects of Tube Wall Thickness}

Fig. (6) shows the relationship of ultimate load with inserting depth of casing joint of square steel tube for 20-25 joints with $1 \mathrm{~mm}$ and $2 \mathrm{~mm}$ tube wall thickness. For the joints with $1 \mathrm{~mm}$ tube wall thickness, the measured value and simulated value of the ultimate load of the joints both increase with inserting depth increasing. The measured value and simulated value fit well. For the joints with $2 \mathrm{~mm}$ tube wall thickness, the measured value of the ultimate load of the joints does not significantly increase. But the simulated value increases obviously. The measured value agrees poor with the simulated value. The ultimate load can be improved

Table 4. Comparisons of Ultimate Load and Displacement

\begin{tabular}{|c|c|c|c|c|c|c|}
\hline \multirow{2}{*}{ Specimen Number } & \multicolumn{3}{|c|}{ Ultimate Load (kN) } & \multicolumn{3}{c|}{ Ultimate Displacement (mm) } \\
\cline { 2 - 6 } & Measured Value & Simulated Value & Errors & Measured Value & Simulated Value & Errors \\
\hline \hline $25-20-1-1$ & 2.25 & 2.09 & $-7.66 \%$ & 21 & 23 \\
\hline $25-20-2-1$ & 2.25 & 2.253 & $0.13 \%$ & 36 & 22.08 \\
\hline $25-20-3-1$ & 2.5 & 2.84 & $11.97 \%$ & 21 & $38.67 \%$ \\
\hline $25-20-4-1$ & 2.5 & 3.06 & $18.30 \%$ & 17 & 18.76 \\
\hline $25-20-2-2$ & 4.5 & 4.06 & $-10.84 \%$ & 40 & 15.7 \\
\hline $25-20-3-2$ & 5.25 & 6.2 & $14.77 \%$ & 31 & 28.32 \\
\hline $25-20-4-2$ & 4.75 & 6.82 & $37.75 \%$ & 13 & $56.25 \%$ \\
\hline $30-25-1-2$ & 1.725 & 2.17 & $20.51 \%$ & 33.5 & $30.97 \%$ \\
\hline $30-25-2-2$ & 6.5 & 6.23 & $-4.33 \%$ & 17 & 25.14 \\
\hline $30-25-3-2$ & 7.45 & 9.98 & $25.35 \%$ & 15.5 & 35.4 \\
\hline $30-25-4-2$ & 6.925 & 12.07 & $42.63 \%$ & 18.25 & $-94.62 \%$ \\
\hline $30-25-5-2$ & 8.6 & 12.39 & $30.48 \%$ & 24.25 & $41.00 \%$ \\
\hline $30-25-6-2$ & 7.075 & 12.574 & $43.73 \%$ & 19.5 & $-57 \%$ \\
\hline
\end{tabular}




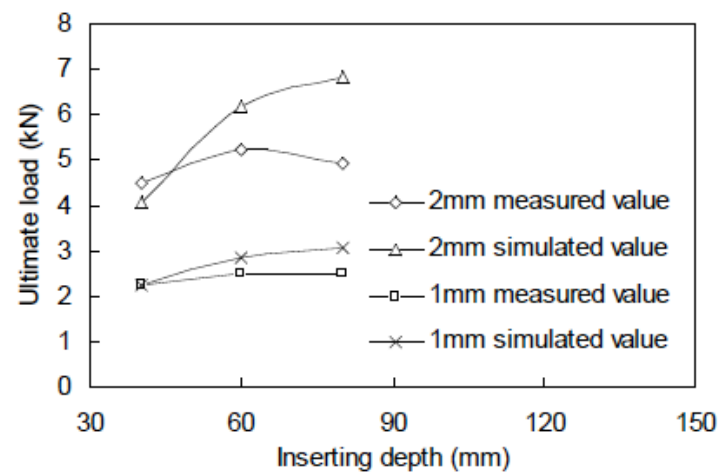

Fig. (6). Ultimate load $v s$. inserting depth curve of the joints with 1 $\mathrm{mm}$ and $2 \mathrm{~mm}$ tube wall thickness.

by increasing tube wall thickness. But it's suggested keep consistent wall thickness of inside tube and outside tube. The reason is that the ultimate load of the joints depends on the flexural rigidity of inside tube.

\section{(2) Effects of Inserting Depth}

Fig. (7) shows the relationship of ultimate load with inserting depth of casing joint of square steel tube with $25 \mathrm{~mm}$ inside tube edge length and $30 \mathrm{~mm}$ outside tube edge length. The measured value and simulated value of the ultimate load of the joints both increase with inserting depth increasing. The simulated value of the ultimate load is higher than the measured value when the inserting depth is more than 2 times inside tube edge length. The simulated value of the ultimate load tends to be stable when the inserting depth is greater than or equal to 4 times inside tube edge length.

\section{(3) Effects of Tube Edge Length}

Fig. (8) shows the relationship of ultimate load with inserting depth of casing joint of square steel tube with different tube edge length. It can be seen that the measured value and simulated value of the ultimate load of the joints both increase significantly with tube edge length increasing. The reason is that the flexural rigidity increases with tube edge length increasing.

\subsection{Analysis of Ultimate Vertical Displacement \\ (1) Effects of Tube Wall Thickness}

Fig. (9) shows the relationship of ultimate displacement with inserting depth of casing joint of square steel tube for

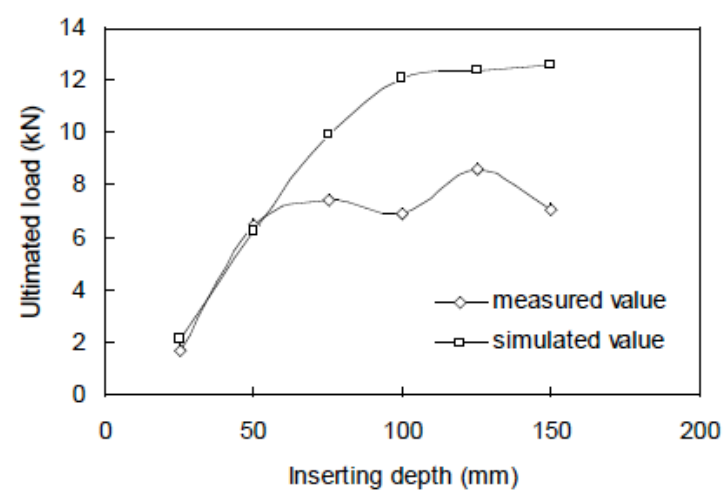

Fig. (7). Ultimate load $v s$. inserting depth curve of the 25-30 joints.

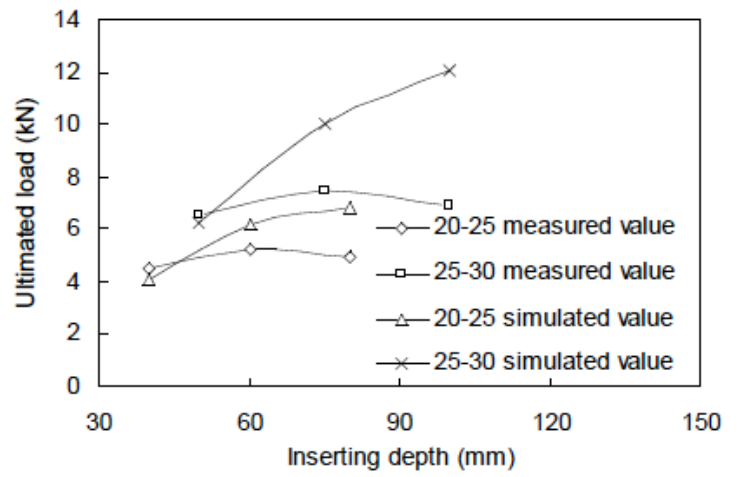

Fig. (8). Ultimate load $v s$. inserting depth curve of the joints with different tube edge length.

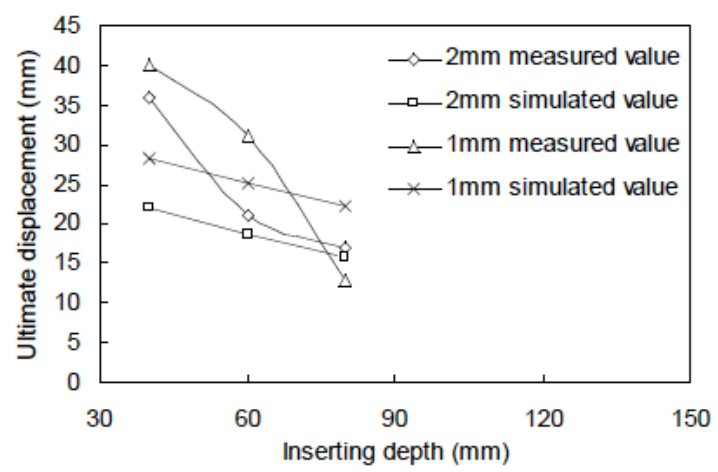

Fig. (9). Ultimate displacement $v$ s. inserting depth curve of the joints with $1 \mathrm{~mm}$ and $2 \mathrm{~mm}$ tube wall thickness.

20-25 joints with $1 \mathrm{~mm}$ and $2 \mathrm{~mm}$ tube wall thickness. The measured value and simulated value of casing joints fit well. But in general, the measured value is higher than the simulated value. The reason is that the slip between tube and supports, and between tube and tube occurs. The vertical displacement of the joints decreases with inserting depth increasing. The reason is that the flexural rigidity of the joints increases with inserting depth increasing. The vertical displacement of the joints increases with the tube wall thickness decreasing.

\section{(2) Effects of Inserting Depth}

Fig. (10) shows the relationship of ultimate displacement with inserting depth of casing joint of square steel tube with $25 \mathrm{~mm}$ inside tube edge length and $30 \mathrm{~mm}$ outside tube edge length.

It can be seen that the measured value and simulated value of the ultimate displacement of the joints both present the trend of decreasing-increasing-decreasing with inserting depth increasing. The measured value agrees well with the simulated value when the inserting depth is equal to $1,2,3,4$ times inside tube edge length. But the measured value is higher than the simulated value when the inserting depth is equal 5, 6 times inside tube edge length. The reason is that the flexural rigidity of the joints increases with inserting depth increasing. When inserting depth belongs to the interval of 2 times and 4 times inside tube edge length, the ultimate displacement of the joints is less than that of single tube, which indicates that the outside tube improve the flexural rigidity of the joints. When inserting depth is more than 4 times inside tube edge length, the ultimate displacement of 


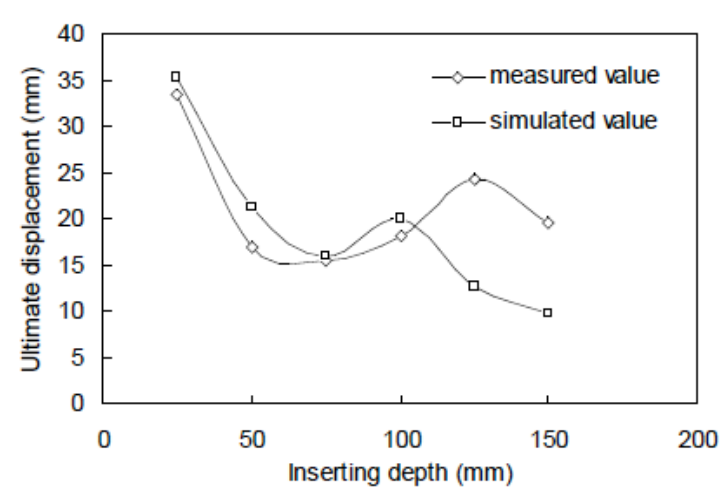

Fig. (10). Ultimate displacement $v s$. inserting depth curve of the 2530 joints.

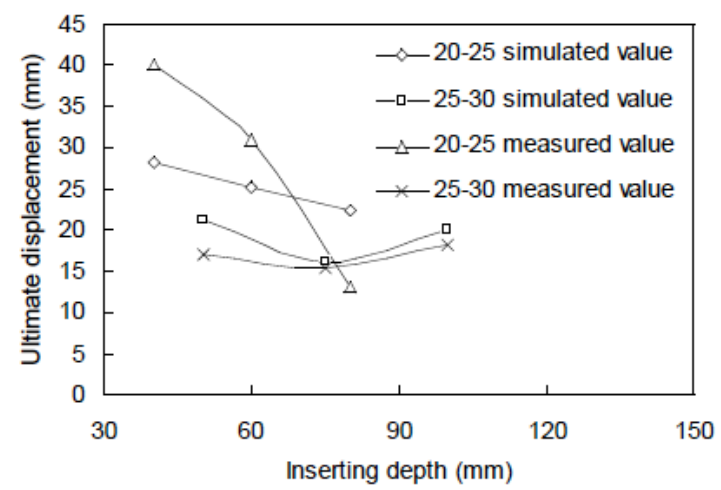

Fig. (11). Ultimate displacement vs. inserting depth curve of the joints with different tube edge length.

the joints increases due to contact area increasing which leads to the slip increasing.

\section{(3) Effects of Tube Edge Length}

Fig. (11) shows the relationship of ultimate displacement with inserting depth of casing joint of square steel tube with different tube edge length. It can be seen that the ultimate displacement decreases with inserting depth increasing. The increasing of tube edge length weakens the measured value and simulated value of the ultimate displacement. The reason is that the increasing of the tube edge length improves the flexural rigidity of the joints.

\section{CONCLUSIONS}

The flexural behavior of casing joint of square steel tube was studied in this paper and with consideration of geometric nonlinearity, material nonlinearity and contact nonlinearity, the finite element analysis software ANSYS/LS-DYNA was used to study the failure modes, ultimate load and flex- ural rigidity of casing joint of square steel tube. By changing the parameters of joints, it's analyzed the rules that flexural rigidity and ultimate load change with different parameters and the following points can be concluded.

(1) The ultimate flexural capacity increases with inserting depth increasing. When inserting depth is more than 4 times inside tube edge length, the ultimate load tends to be a certain value.

(2) The ultimate vertical displacement decreases with inserting depth increasing.

(3) The ultimate load of casing joints of square steel tube is proportional to tube shear strength, tube wall thickness, inserting depth, and tube edge length.

\section{ACKNOWLEDGMENTS}

Support for this research by the National Program for New Century Excellent Talents in University No. NCET-080542, the National Natural Science Funds No. 50979108, the Research Start-up Foundation of CAU No. 2008041, Chinese Universities Scientific Fund No. 2009-3-11, and the National Science Support Projects No. 2008BADC4B03.

\section{REFERENCES}

[1] M. Yajima, H. Akiyama, and N. Akiyama, "Experimental study on strength of joints in steel tubular structures", Journal of Sciety of Steel Construction, vol. 10, pp. 102-110, October 1974.

[2] J. C. Paul, "Ultimate resistance of unstiffened mutiplanar tubular TT- and KK- joints", Journal of Structural Engineering, vol. 120, pp. 2853-2870, October 1994.

[3] K. J. R. Rasmussen, "Recent research on stainless steel tubular structures", Journal of Constructional Steel Research, vol. 54, pp. 75-88, January 2000.

[4] R. J. Qian, “Applying strain energy density factor theory to propagation estimating of surface crack in tubular T-joints", Engineering Fracture Mechanics, vol. 53, pp. 849-851, June 1996.

[5] M. R. Morgan, and M. M. K. Lee, "New parametric equations for stress concentration factors in tubular K-joints under balanced axial loading”, International Journal of Fatigue, vol. 19, pp. 309-317, April 1997.

[6] C. K. Lee, L. S. Tjhen, and C. S. Ping, "Numerical models verification of cracked tubular T, Y and K-joints under combined loads", Engineering Fracture Mechanics, vol. 72, pp. 983-1009, July 2005.

[7] Y. S. Choo, X. D. Qian, and J. Wardenier, "Effects of boundary conditions and chord stresses on static strength of thick-walled CHS K-joints”, Journal of Constructional Steel Research, vol. 62, pp. 316-328, April 2006.

[8] B. Shen, "Theoretical and Experimental Studies on Static Stability Behavior of Axially Compressed Sleeved Column", Ph. D. thesis, Tongji University, Shanghai, China, April 1, 2007.

[9] L. L. Zhang, "Study on the Load-carrying Capability of the Casing Plug Joint of Tubular Steel Structures", M. S. thesis, China Agricultural University, Beijing, China, May 15, 2006.

[10] Y. H. Wu, "Study on the Performance of the Casing Plug Joint of Square Steel Tube Structures", M. S. thesis, China Agricultural University, Beijing, China, May 15, 2009.

This is an open access article licensed under the terms of the Creative Commons Attribution Non-Commercial License (http://creativecommons.org/licenses/by-nc/3.0/) which permits unrestricted, non-commercial use, distribution and reproduction in any medium, provided the work is properly cited. 